\title{
Los orígenes de la arquitectura telefónica en España: las centrales madrileñas del «Grupo Peninsular»
}

\author{
Francisco Javier García Algarra, \\ Óscar da Rocha ARANDa, \\ Marta Saliné I Perich
}

\section{The origins of telephone architecture in Spain: Central offices of Group «Peninsular» In Madrid}

RESUMEN

El desarrollo del negocio telefónico en España fue lento y hay muy pocos edificios diseñados como centrales telefónicas antes de 1924. Este artículo describe el conjunto de tres centrales que el Grupo Peninsular construyó en Madrid entre 1910 y 1917, siguiendo las reglas e ideología sobre arquitectura de American Telephone and Telegraph que inspiraron a las pequeñas empresas privadas europeas de ese periodo.

PALABRAS CLAVE

Central telefónica, mosaicos, electicismo
ABSTRACT

The development of telephone business in Spain was slow, and there are few buildings designed as telephone exchanges before 1924. This paper describes the set of three exchanges that the Group «Peninsular» built in Madrid between 1910 and 1917, following the practices and ideology on architecture of American Telephone and Telegraph that inspired the small private owned European Companies of that time.

KEYWORDS Telephone Exchange, mosaics, eclecticism

\section{INTRODUCCIÓN}

Las centrales telefónicas son un tipo de edificación concebido para albergar los equipos que permiten prestar un servicio imprescindible para la sociedad contemporánea. Gran parte de las instalaciones fabriles de las primeras décadas del siglo XX han desaparecido por obsolescencia. La protección de este patrimonio ha favorecido la investigación y el aprecio de sus valores estéticos. Sin embargo, el

* Francisco Javier García Algarra, uned, departamento de Historia del Arte. Óscar da Rocha ARANDA, Coordinador del Colegio de Arte Contemporáneo del Instituto Superior de Arte IIArt. MARTA SALINÉ I PERICH, Conservadora de los Museus d'Esplugues de Lobregat. 
carácter industrial de los edificios telefónicos no se percibe con facilidad desde su exterior y en buena parte continúan prestando el mismo servicio para el que se proyectaron hace décadas.

En este artículo se estudia el conjunto más antiguo de España, las centrales construidas en Madrid por el grupo de empresas conocido como la «Peninsular». Este conglomerado de origen catalán fue uno de los pocos privados en Europa que llegó a plantearse un programa de construcciones de cierta envergadura.

La investigación aporta material inédito que permite enmarcar los proyectos dentro de la lógica del negocio de la compañía propietaria y ayuda a interpretar su refinada estética.

Una parte introductoria describe el estado de la arquitectura madrileña en los años iniciales del reinado de Alfonso XIII, con especial atención a las construcciones comerciales e industriales. A continuación se explican las características de la arquitectura telefónica y se incluye una breve historia del Sistema Peninsular. Establecido este marco de referencia se analizan los edificios.

\section{ARQUITECTURA EN MADRID A COMIENZOS DEL SIGLO XX: UNIDAD Y DIVERSIDAD DEL ECLECTICISMO}

En el Madrid de principios del siglo XX, cuando se erigieron las primeras centrales del Grupo Peninsular, el panorama arquitectónico estaba caracterizado por la existencia de una serie de corrientes estilísticas muy diversas, que confluían y se integraban en lo que se ha convenido en denominar eclecticismo.

Hay que entender el eclecticismo como un complejo movimiento arquitectónico, surgido alrededor de mediados del siglo XIX, que alcanzó su apogeo en las últimas décadas de aquella centuria y perduró hasta bien entrada la siguiente. En las concepciones más formalistas la condición ecléctica de la arquitectura se define por la utilización o combinación de elementos decorativos procedentes de casi todos los estilos arquitectónicos pretéritos o coetáneos. Sin embargo, el eclecticismo se caracteriza específica y verdaderamente por la aplicación de esos mismos elementos en edificios que responden a las necesidades de su propia época. ${ }^{1}$

Para sus contemporáneos el eclecticismo se expresaba mediante los diversos revestimientos decorativos de los edificios, que se convertían en variantes diferenciadas, de forma que cada una de ellas podía ser considerada como un estilo en sí mismo. Así, proliferaron una serie de categorías, que no eran otra cosa sino

\footnotetext{
${ }^{1}$ Véanse: NAVASCUÉS PALACIO, P. Arquitectura y arquitectos madrileños del siglo XIX. Madrid: Instituto de Estudios Madrileños, 1973 y Arquitectura Española (1808-1914), Summa Artis, vol. XXV. Madrid: Espasa Calpe, 1993. HERNANDO, J. Arquitectura en España 1770-1900. Madrid: Cátedra, 1989 e ISAC, Á. Eclecticismo y pensamiento arquitectónico en España. Discursos, revistas, congresos (18461919). Granada: Diputación Provincial, 1987.
} 
meras calificaciones ornamentales extraídas de arquitecturas precedentes, caso de los llamados estilos francés, inglés, español, de los Luises, ojival, etc., o coetáneas, como sucedió con el estilo moderno que solía incluir detalles modernistas. Tal precisión clasificatoria resulta hoy artificiosa e incluso falsa, puesto que en todos los casos nos hallamos ante manifestaciones de un único estilo, el eclecticismo.

En España, se gestó a mediados del siglo XIX como complemento, respuesta y alternativa al tardoneoclasicismo y al historicismo de inspiración medieval, que por aquellos años estaban empezando a dar signos de agotamiento. La posibilidad de emplear, e incluso combinar en un mismo edificio, diversos estilos se convirtió en el camino que siguió la arquitectura española en general, y madrileña en particular, durante casi un siglo². La flexibilidad de la actitud ecléctica facilitó posturas no excluyentes, por lo que convivieron corrientes tan dispares como el neoclasicismo, el historicismo medieval y el modernismo.

Así, la arquitectura inspirada en la Edad Media monopolizó las construcciones religiosas. Por su prestigio y monumentalidad, el clasicismo en todas sus variantes se aplicó a los edificios públicos o representativos del poder político o económico, y el refinamiento del Barroco y el Rococó definieron la imagen más apropiada para palacetes, hoteles, viviendas y lugares de esparcimiento de la nobleza y la alta burguesía.

Mención aparte merece el caso de la arquitectura industrial y comercial, cuyas peculiaridades funcionales permitieron adoptar soluciones estilísticas más atrevidas. Este ámbito constituye el mejor reflejo de la ambivalencia y flexibilidad del eclecticismo, ya que en él se integran necesidades funcionales y estéticas que no se dan en otras tipologías: por una parte prima el utilitarismo, pero por otra no se renuncia a la representatividad. En su momento algunos resultados de esta combinación dieron como fruto edificios singulares, organizados mediante espacios de gran funcionalidad pero ornamentados exterior, y a veces interiormente, con llamativos elementos en cuya definición los repertorios eclécticos más originales gozaron de gran protagonismo. ${ }^{3}$

Esta asociación fue posible porque se trataba de un campo en el que la tradición arquitectónica apenas tenía influencia, ya que desde el siglo XVIII había sido monopolio casi exclusivo de los ingenieros. No obstante, a partir de finales del siglo XIX los arquitectos empezaron a considerar que estas construcciones no debían abandonarse a la total desornamentación de la que se acusaba a los ingenieros; por ello, resultaba imprescindible dignificar su arquitectura revistiéndola de un lenguaje decorativo.

\footnotetext{
2. ALONSO PEREIRA, J. R. Madrid de Corte a Metrópoli. 1898-1931. Madrid: Comunidad de Madrid, 1985.

${ }^{3}$ Acerca del origen y transformación del modernismo en el contexto ecléctico de la arquitectura madrileña véase ROCHA ARANDA, Ó. da. El modernismo en la arquitectura madrileña. Génesis y desarrollo de una opción ecléctica. Madrid: CSIC, 2009.
} 
Los empresarios también fueron conscientes de tal necesidad, al percibir los valores de representatividad y prestigio que la aplicación de un estilo aportaba a sus fábricas o comercios. Las diversas actividades industriales iban acompañadas de una proyección comercial, por lo que el aspecto adquiría importancia como elemento publicitario, sobre todo cuando los edificios estaban ubicados en el interior de las ciudades. Esta preocupación estética supuso la rápida incorporación de los arquitectos a la realización de esta clase de obras.

Los componentes industrial y comercial (a veces también residencial) que condicionaron la gestación de estos edificios propiciaron la adopción de soluciones híbridas que combinaban lo funcional con lo decorativo. A comienzos del siglo XX, el eclecticismo más renovador, y especialmente la ornamentación modernista, eran las opciones que mejor se adaptaron a las necesidades descritas. Al tiempo que incorporaban los nuevos sistemas y materiales constructivos ofrecían una imagen moderna y representativa. Las centrales telefónicas analizadas aquí, son una muestra de esta concepción de la arquitectura.

\section{ORIGEN Y CARACTERÍSTICAS DE LA ARQUITECTURA TELEFÓNICA}

La arquitectura telefónica nació para atender el negocio que se desarrolló con la invención de Alexander Graham Bell en 1876. El primer servicio comercial se inauguró en New Haven (Conneticut) en enero de 1878. Al principio, los equipos necesarios se instalaban en edificios preexistentes, pero ya a mediados de la década de los 80 del siglo XIX, se diseñaron las primeras grandes centrales en Nueva York, Chicago o Saint Louis. La telefonía era un negocio privado, dominado de forma abrumadora por el Bell System, grupo de empresas cuya cabecera era American Telephone \& Telegraph (AT\&T).

En Europa la evolución fue mucho más lenta ${ }^{4}$. Algunos países integraron de forma inmediata el teléfono en sus administraciones postales, como el Imperio Alemán o Suiza. Francia y el Reino Unido, que concedieron al principio concesiones urbanas a pequeñas empresas privadas, terminaron nacionalizando el servicio. Esta fue la evolución general, con algunas excepciones en los países nórdicos y Holanda. Las instalaciones telefónicas europeas compartieron edificios con el correo y el telégrafo o fueron diseñadas por los mismos arquitectos, con igual estética.

\footnotetext{
${ }^{4}$ El retraso de la telefonía europea fue objeto de reflexión muy pronto. El ingeniero británico Alfred Rosling publicó en 1895 «The Telephone Systems of the Continent of Europe», una monografía sobresaliente en la que describe las redes de todos los países. Otro ingeniero, Herbert Laws Webb, escribió 15 años después «The Development of the Telephone in Europe», desde una perspectiva muy crítica con la propiedad estatal.
} 
«Fuera de Norteamérica, el enfoque de los edificios telefónicos fue mucho más conservador y modesto en los años que precedieron a la Segunda Guerra Mundial. [..] Las oficinas telefónicas europeas parecían más cuarteles que palacios. ${ }^{5}$

En el sur de Europa se prolongó durante más tiempo el sistema de concesiones porque los estados no disponían de recursos financieros suficientes para construir una red alternativa a la telegráfica. Esto produjo un notable atraso en Italia, España, Portugal o los Balcanes. En el caso español, no existen edificios telefónicos construidos con ese propósito antes de 1911.

Una central es una pequeña factoría, todo el diseño se supedita a dar servicio a la maquinaria, facilitando la instalación, conservación y posteriores ampliaciones. Resulta difícil percibir desde el exterior su naturaleza industrial, oculta tras envoltorios con aspecto de palacio renacentista, casita neogeorgiana o rascacielos grandioso, siempre parecidos al entorno en que se encuentran. ${ }^{6}$

Desde finales del siglo XIX se adoptó en Estados Unidos la norma de adecuar la apariencia de las centrales al lugar en que se debían construir, para evitar el rechazo del público. Los edificios se convirtieron en símbolo de la compañía y se creó una doctrina sobre su valor representativo. La arquitectura telefónica es un peculiar híbrido de arquitectura industrial y comercial, con un fuerte contraste entre la desnudez funcional de sus interiores y el rico aparato decorativo en las abiertas al público ${ }^{7}$. Ignacio de Cárdenas Pastor, arquitecto del rascacielos de Gran Vía, lo resumió así:

«Difícil comparación tiene el edificio telefónico con otros destinados a fines parecidos, pues si es esencialmente un edificio de carácter industrial, es también una embajada de la Compañía en las ciudades españolas, y ha de ser, como ella, popular, suntuoso, útil y rico. También es un anuncio. Sin el anuncio fracasan hoy en día todas las empresas que del público viven, y un buen anuncio ha de estar enclavado en el mejor lugar de la ciudad.» ${ }^{8}$

Esta preocupación por la función representativa, se advierte en los escasos ejemplos de compañías privadas europeas, como la National Telephone Company británica, incautada en 1912, o las de las capitales de Escandinavia. Es la misma que demostró el Grupo Peninsular en sus edificios.

\footnotetext{
${ }^{5}$ CHAPUIS, R. 100 Years of Telephone Switching, 1878/1960's. IOS Press, 2003, pp. 33-34.

${ }^{6}$ El profesor y crítico Robert Bruegmann dedicó un capítulo de su monografía sobre Holabird \& Roche a sus diseños de centrales en Chicago a principios del siglo XX. BRUEGMANN, R. The Architects and the City. Holabird \& Roche of Chicago, 1880/1918. Chicago: The University of Chicago Press, 1997.

${ }^{7}$ Una exposición sistemática de la doctrina arquitectónica del Bell System se encuentra en Richard Storrs Coe. «Bell System Buildings - an Interpretation», The Bell Telephone Quarterly, vol. VIII, julio de 1929, pp. 201-217.

${ }^{8}$ DE CÁRDENAS PASTOR, I. «EI Departamento de Edificios. Notas de su variada y acertada actuación», Revista Telefónica Española, núm. 8, 1927.
} 


\section{EL SISTEMA PENINSULAR DE TELÉFONOS}

En la telefonía española primitiva destaca el conglomerado de empresas conocido como el Sistema Peninsular. El promotor del grupo era Enrique Parellada Pallás (1865-1924), un empresario ligado a la creación de las primeras sociedades de suministro eléctrico ${ }^{9}$. Practicó un liderazgo muy personalista, las referencias aduladoras son frecuentes en las noticias relacionadas con la Compañía.

«Es hombre que a la mayor energía de carácter sabe unir la mayor amabilidad para con todos los funcionarios a sus órdenes, con lo cual ha logrado que éstos, desde los más humildes a los más elevados, vean en él juntamente al jefe y al amigo. 10

Hay ejemplos de este culto al líder en los contemporáneos Theodore Vail (1845-1920) en American Telephone and Telegraph ${ }^{11}$ o el sueco Henrik Tore Cedergen (1853-1909), dueño de la Stockholms Allmänna Telefonaktiebolag ${ }^{12}$.

La Compañía Peninsular de Teléfonos (CPT) operaba la red interurbana, abierta a la iniciativa privada en 1891 por Francisco Silvela ${ }^{13}$. Se fundó en 1894 para operar la concesión de la red del Nordeste que incluía el cuadrante delimitado por Bilbao, Madrid y Valencia ${ }^{14}$. El Sistema era propietario de las dos redes urbanas más importantes. La Sociedad General de Teléfonos (SGT) explotaba la de Barcelona desde 1890. La de la capital se adquirió en 1895 a la Sociedad de Teléfonos de Madrid, cuyos activos pasaron a la nueva Compañía Madrileña de Teléfonos (CMT). La estrategia de expansión de Parellada se basó en ir haciéndose con el control de otras concesiones. Hacia 1910 controlaba la mitad de las líneas telefónicas españolas, porcentaje que creció hasta el $58 \%$ en $1920^{15}$. A partir de 1921 las licencias de operación empezaron a revertir al Estado. En 1924 Parellada vendió sus acciones a la International Telephone and Telegraph ${ }^{16}$ que acabó integrando estas empresas en la CTNE.

\footnotetext{
${ }_{9}^{9}$ MALUQUER DE MOTES BERNET, J. «Los pioneros de la segunda revolución industrial en España. La Sociedad Española de Electricidad (1881-1894)», Revista de Historia Industrial, núm. 2, 1992 , pp. 121-142.

10 «La Compañía Peninsular de Teléfonos», $A B C, 25$ de marzo de 1911, pág. 10.

${ }^{11}$ MARCHAND, R. Creating the Corporate Soul: The Rise of Public Relations and Corporate Imagery in American Big Business. Berkeley (California), University of California Press, 1998. JOHN, RICHARD. Telephomania: The Contested Origins of the Urban Telephone Operating Company in the United States, 1879/1894. University of Illinois at Chicago. Publication Number: GCP/05/02, 2005.

${ }^{12}$ HELGESSON, C. Making a Natural Monopoly. The configuration of a Techno-Economic Order in Swedish Telecommunications. Stockholm School of Economics, 1999.

${ }^{13}$ Gaceta de Madrid, núm. 80, 21 de marzo de 1891, pp. 884-886.

${ }^{14}$ CALVO CALVO, A. «El teléfono en España antes de Telefónica (1877-924)», Revista de Historia Industrial, núm. 3, 1993, pág. 71.

${ }^{15}$ PÉREZ YUSTE, A. La Compañía Telefónica Nacional de España en la Dictadura de Primo de Rivera (1924/1930). (Tesis Doctoral s.p.), Universidad Politécnica de Madrid, 2004, pág. 89.

16 PÉREZ YUSTE, A. Op. Cit. pp. 130-132.
} 


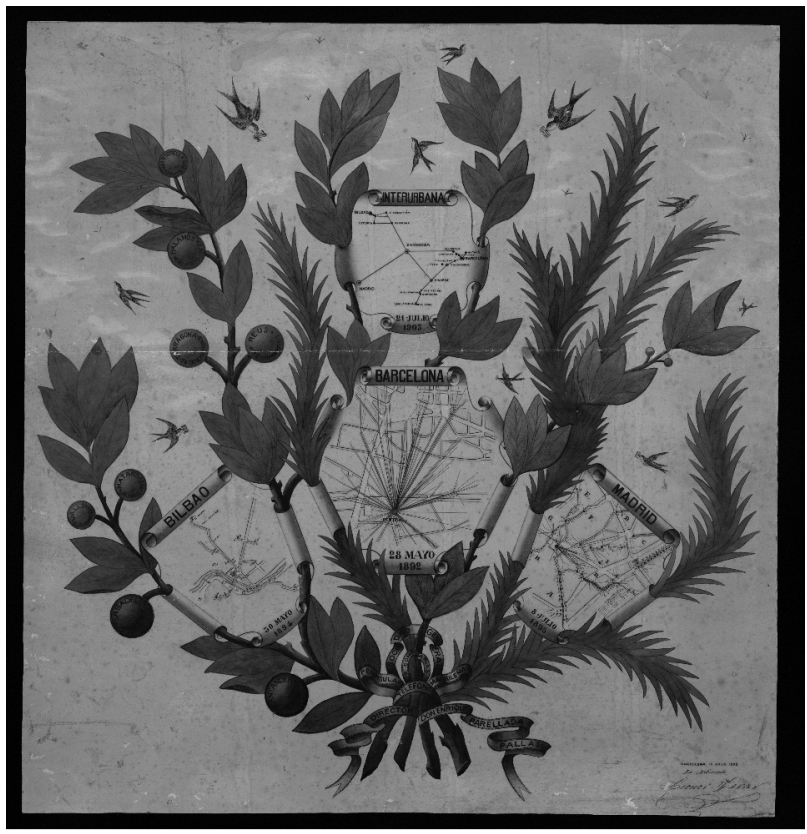

Figura 1: llustración de Leonor Ferrer, de 1906, con una alegoría del Sistema Peninsular. En la parte superior se aprecia el esquema de la red interurbana del Nordeste, la primera que se construyó. En la fila inferior mapas de las tres concesiones urbanas más importantes: Bilbao, Barcelona y Sevilla. Institut Cartogràfic de Catalunya, registro RM.281982.

La estrategia de relaciones públicas de la CPT reproducía a escala mucho menor la de AT\&T: cuidado de las apariciones en prensa, teatralización de las inauguraciones y preocupación por la estética y la arquitectura como elementos de la imagen de marca. ${ }^{17}$

La Peninsular adquirió la «Casa Laribal» en Barcelona, diseñada en 1902 por Lluís de Miquel i Roca ${ }^{18}$ para convertirla en su sede principal. La reforma para convertirla en oficinas y central telefónica (1910) corrió a cargo de Enric Sagnier i Villavecchia (1858-1931).

La distribución era la común en una central telefónica manual: locutorios y oficina comercial en la planta baja, administración en el entresuelo y salas de equipos y operadoras en la parte superior. El cableado salía por la cubierta y se distribuía con un templete de hierro. La decoración desempeñaba un papel importante en un edificio que se había concebido como representación del Sistema.

${ }^{17}$ GARCÍA ALGARRA, F. J. «The American influence in Telefónica's public relations strategy during the 20's and 30's". HISTELCON, Madrid, 2010.

${ }^{18}$ Aunque durante mucho tiempo se ha atribuido a Pere Falqués i Urpí, en la ficha del Ajuntament de Barcelona se indica que los planos son de Lluís de Miquel i Roca, Falqués firmó como arquitecto municipal. 


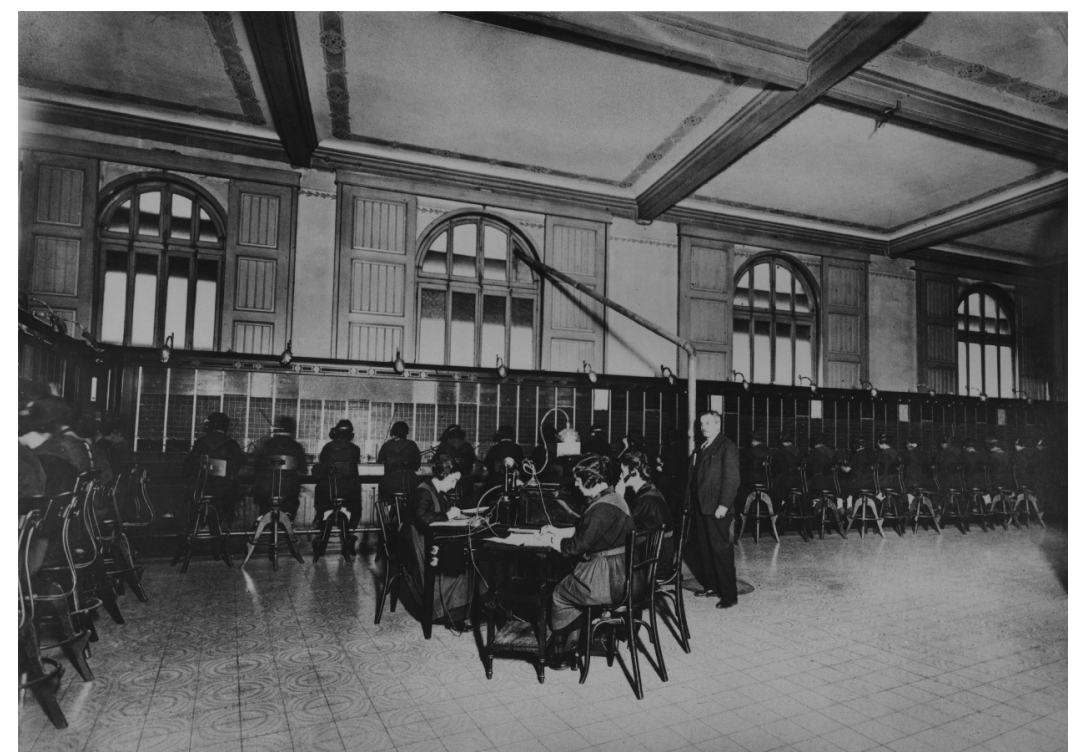

Figura 2: Sala de conmutación de la central de Avinyó en 1925. Archivo Histórico Fotográfico de Telefónica, negativo R-04203.

\section{EL PRIMER EDIFICIO TELEFÓNICO, LA CENTRAL DE INTERURBANA DE MADRID}

En 1895 se inauguró la línea Madrid-Zaragoza-Barcelona de la Red Telefónica del Nordeste de España, propiedad de la Peninsular. La central interurbana de la capital se instaló en un local de la calle Alcalá $12^{19}$. En una época en la que los únicos medios de comunicación de masas eran impresos, esta central cobraba protagonismo en momentos singulares. El vestíbulo se convertía en un punto de cita de los periodistas, ya se tratase de una crisis política ${ }^{20}$ o del sorteo de la lotería de Navidad.

Para atender la demanda creciente y desarrollando la política de imagen que había comenzado con la sede barcelonesa la Peninsular decidió construir el primer edificio diseñado y concebido para ser central telefónica en España. Se levantó entre 1910 y 1911 en la calle Alcalá número 1, sobre un solar de tan solo 500 m². Los planos del proyecto están firmados por Manuel Costilla Pico (un arquitecto semidesconocido titulado en Madrid en 1907) y la dirección de obra correspondió a Enrique Martí Perla ${ }^{21}$, cuya relación con el grupo continuó como ya veremos.

\footnotetext{
${ }^{19}$ Hay dos grabados de su interior en La Ilustración Española y Americana, núm. XVII, 8 de mayo de 1895 , p. 280.

${ }^{20}$ En la misma revista aparece una recreación artística de esta situación, en la página 349 del ejemplar de 15 de diciembre de 1906.

${ }^{21}$ Tal y como refleja el expediente de construcción conservado en el Archivo de Villa de Madrid (AVM) legajo 17-399-4.
} 


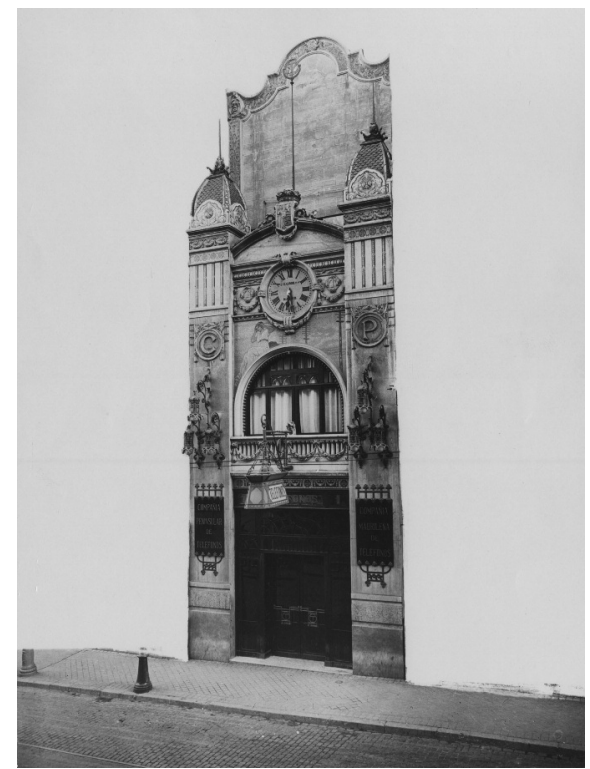

Figura 3: Fachada de la central interurbana en Alcalá 1, en 1924. Fotografía de Marín, Archivo Histórico Fotográfico de Telefónica, negativo R-04814.

La fachada era medianera y muy estrecha, así que para conseguir el efecto representativo que deseaban los propietarios se utilizó una riquísima decoración, dominada por el mosaico de Lluís Brú i Salelles (1868-1952)22. Las imágenes conservadas de esta fachada (fundamentalmente el plano original firmado por Manuel Costilla y varias fotografías publicadas en prensa o custodiadas en el archivo histórico de Telefónica), muestran un alzado de cuidado diseño y elaborada ornamentación. Así lo describió el diario $A B C$ :

«La fachada exterior ofrece aspecto agradabilísimo con la visualidad de sus líneas, con la acertada composición artística general, inspirada en el estilo moderno. Una arcatura amplia que cobija la puerta de entrada y el único hueco exterior del edificio es el elemento principal de la fachada. Dos pilastrones rematados por esbeltos cupulines, que destacan su silueta sobre el fondo de un cerramiento posterior que corona aquella parte de la composición, flanquean y soportan la arcatura antes mencionada y el piso del frontis que esta sostiene.»23

Resulta significativa la mención expresa al «estilo moderno», como caracterización estilística general del edificio, lo que, acompañado por otras alusiones

\footnotetext{
${ }^{22}$ Considerado uno de los mosaicistas más importantes del Modernismo Catalán. Fue un personaje polifacético: escenógrafo, pintor para las artes decorativas y mosaicista en su etapa final. En las mismas fechas que la central de Madrid trabajó en una obra tan singular del Modernismo Catalán como el friso del Palau de la Música Catalana en Barcelona (1905-1910).

${ }^{23}$ «La Compañía Peninsular de Teléfonos», $A B C, 25$ de marzo de 1911, pág. 10.
} 


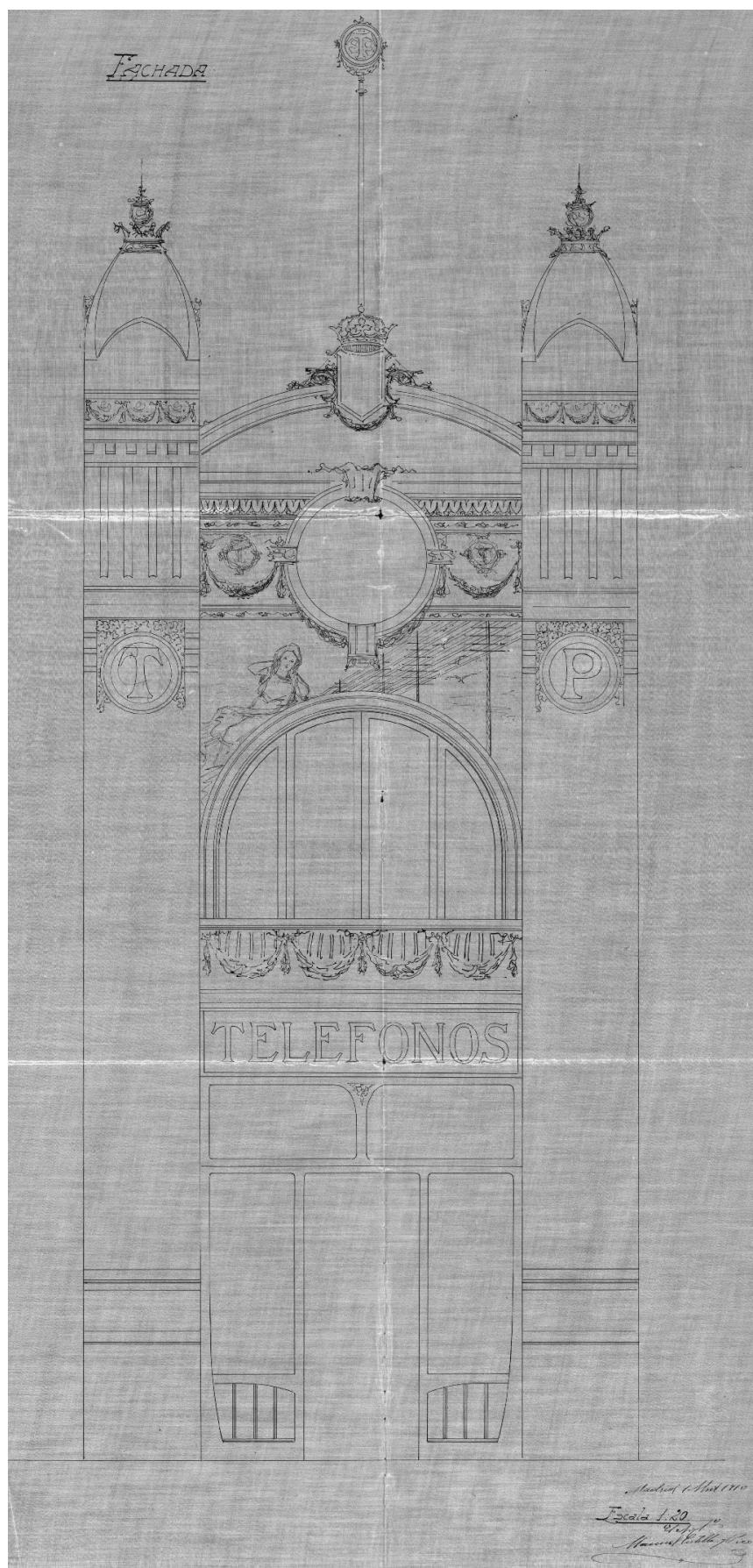

Figura 4: Plano original de la fachada de Alcalá 1910. Archivo de la Villa de Madrid, AVM 17-399-4-0028 
posteriores al «gusto inglés» o al «estilo Luis XVI» de diversas dependencias interiores, demuestra que la decoración de esta central respondía a patrones eclécticos. También es sobresaliente la calidad de los detalles ornamentales de la fachada, muchos de ellos de inspiración modernista, especialmente los diferentes letreros, carpinterías, apliques, lámparas y herrajes, estos debidos al trabajo de la madrileña casa de Eusebio Calvo; e incluso el reloj central, realizado por la también madrileña, y ya entonces muy prestigiosa, firma Girod.

Capítulo especial merece el análisis del mosaico modernista realizado por Lluís Brú, donde se representa una «alegoría de la telefonía».

En el Archivo Municipal de Esplugues de Llobregat (AMEL) se conserva documentación inédita sobre el trabajo de Brú en este edificio: un presupuesto con fecha del 26 de enero de $1910^{24}$, dos dibujos a escala real de gran belleza y la factura de realización de los mosaicos con fecha 26 de septiembre del mismo año. Esta permite verificar la obra realizada y conocer una decoración hoy desaparecida. Podemos dividir la información en dos tipos de producciones. En primer lugar el gran mosaico mixto que actuaba como reclamo comercial ${ }^{25}$, invitando al ciudadano al interior del edificio para usar sus servicios:

«Construcción en mosaico veneciano y cerámico de un paramento para sobre puerta comprendiendo los proyectos, dibujos, armazones de hierro y embalajes. Coste: $1.380 .-\gg 26$

Este tipo de piezas dotaban de luminosidad y color a la fachada mediante la luz reflejada sobre esta base vidriada. El cristal de tipo veneciano era el material de mayor coste ya que se importaba de Italia. Su color más intenso sobresalía y acentuaba las zonas que necesitaban mayor detalle. En el plafón de la fotografía se aprecia la representación de una dama realizando las funciones de telefonista. Posiblemente el material veneciano se hallaba en la cara y en las manos, zonas laboriosas que necesitaban un especial detalle, mientras que la cerámica debía ofrecer un cromatismo más uniforme al resto de la pieza.

La figura femenina era el elemento icónico más importante del conjunto. En el citado Archivo hay otro diseño que, pensamos, fue desestimado.

Una segunda parte de la facturación detalla la aplicación de revestimiento cerámico que decora la fachada. En este caso el presupuesto no indicaba su

${ }^{24}$ El presupuesto planteaba acabados en mosaico de oro que finalmente no fueron realizados: «el fondo de esmalte de dorado aumentaría el precio en 875 pesetas».

${ }^{25}$ Estos mosaicos publicitarios, eran comunes en el modernismo barcelonés, como en el «Hotel Metropolitan» de Barcelona (1906-1918) de arquitecto Adolf Ruíz Casamitjana, donde un friso hoy desaparecido reflejaba actividades lúdicas y deportivas. Uno de los más representativos y realizados en las mimas fechas por el mismo Lluís Brú, es el mosaico que corona la fachada del Palau de la Música Catalana en Barcelona (1905-1910) el cual simboliza el canto coral y a la institución que el «Orfeó Català».

${ }^{26}$ El total de la decoración de los mosaicos ascendió a la suma de 2.175, 50 pesetas 


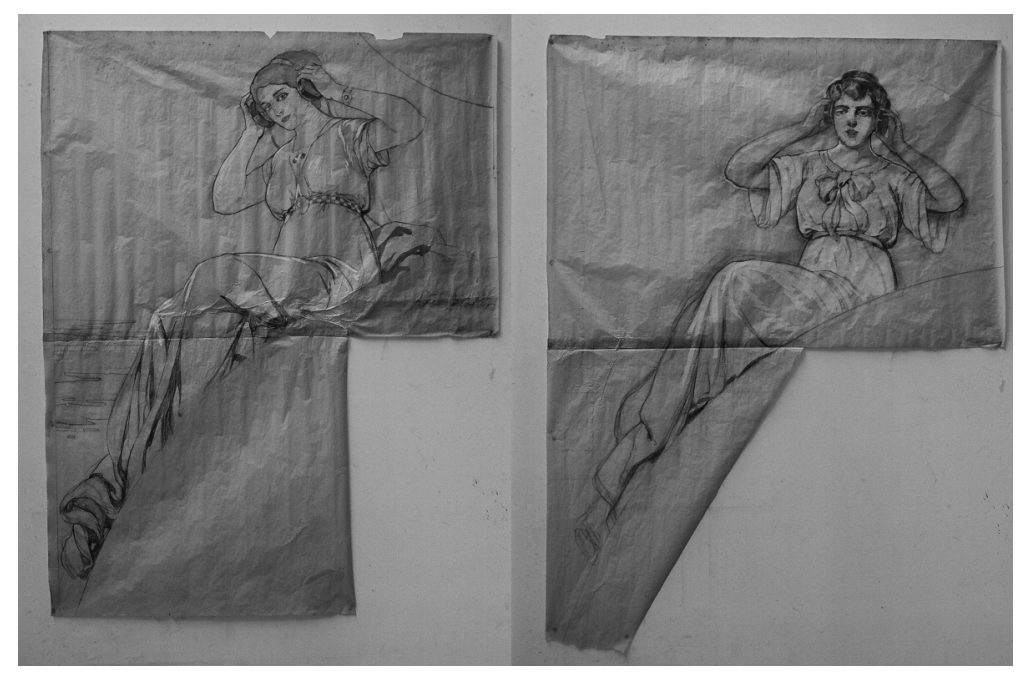

Figura 5: Diseños originales para el mosaico de Alcalá 1, el de la izquierda es el que finalmente se realizó. AMEL, fuente: Taller Lluís Brú. Registros $540(216$ x $164 \mathrm{~cm})$ y $541(209$ x $167 \mathrm{~cm})$

producción y tenemos que entender su aplicación a partir de una nueva valoración del proyecto global.

«Dibujos y construcción en mosaico de un friso para la misma puerta que mide $3,65 \times 0,30$. Coste 200 .

Dibujos y construcción de 4 remates de $1,38 \times 0,80$ con florón de relieve. Coste 480.

Dibujos y construcción de 2 frisos de $1,38 \times 0,30$. Coste 92 .

Dibujo y construcción de 8 tiras para las estrías 1,30 x 0,10. Coste 144.- «

El presupuesto indica que Brú recibió la petición «del arquitecto Enrique Sagnier», lo que lleva a plantearse su participación en este proyecto, sobre todo en el programa ornamental ${ }^{27}$. La influencia catalana es clara, además del mosaico de Brú la fachada estaba recubierta con caliza gris de Figueres y arenisca blanca de Vilafranca del Penedés ${ }^{28}$. En el vestíbulo había una pintura mural con la leyenda «Servicio Rápido», que por el estilo recuerda en gran medida a los anuncios de la Compañía, algunos de los cuales están firmados por Vilaró Hermanos, la misma firma que se encargó de la decoración interior de Avinyó. ${ }^{29}$

\footnotetext{
${ }^{27}$ En la factura se indica: «Por mis trabajos hechos para la Central de Teléfonos en Madrid p. o. d. del Sr. arquitecto D. Enrique Sagnier». Estamos seguros que en este caso el mosaicista no viajó a Madrid para la colocación de los mosaicos desconociendo la ubicación del edificio ya que la publicidad y nota curricular de los años 20 no menciona la calle de la central y sigue atribuyendo la obra a Sagnier.

${ }^{28} \mathrm{ABC}, 25$ de marzo de 1911, p. 10.

${ }^{29}$ La Vanguardia, 28 de enero de 1910, pág. 4.
} 


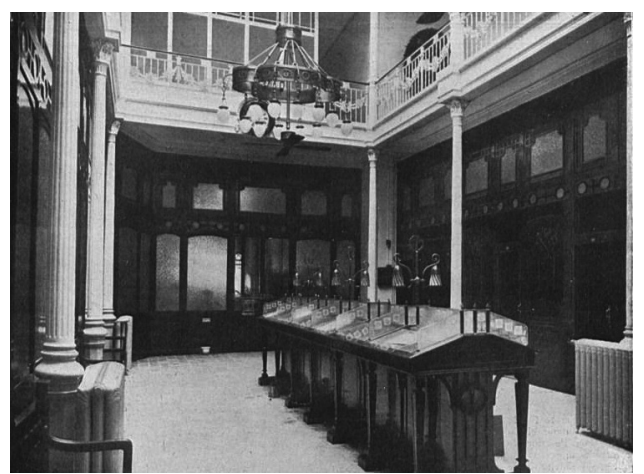

Figura 6: Salón para el público.

Nuevo Mundo, 30 de marzo de 1911, Hemeroteca Municipal de Madrid.

La Compañía cuidó en extremo la inauguración, que tuvo lugar el 25 de marzo de 1911. En las publicaciones del momento aparece repetido un texto descriptivo del edificio, que sin duda fue una nota distribuida a los periodistas en los días previos. La versión más extensa es la de $A B C$, pero se encuentran párrafos idénticos en Blanco y Negro, La Época, El Imparcial, Gaceta de los Caminos de Hierro o Nuevo Mundo, con algunas exageraciones encomiásticas:

«La Compañía Peninsular de Teléfonos, en su deseo de satisfacer cumplidamente las mayores exigencias para la utilización de un servicio tan importante como el teléfono interurbano, ha hecho una instalación espléndida, en la cual no se sabe que admirar más, si la riqueza y el buen gusto de su decorado o la perfección y el acierto en los detalles de todo aquello que al público interesa.»

La distribución interior era muy parecida a la de otras centrales norteamericanas o europeas de principios del siglo XX, con la planta baja abierta al público.

«En el interior, la parte destinada al público tiene adecuado lugar en la planta baja, a la que da acceso el hermoso vestíbulo, decorado con rica ornamentación pictórica, combinada con mármoles de tonos claros que le dan una grata visualidad, ocupando esta habitación las tres primeras crujías del edificio, dando paso al gran patio central, de bellísima perspectiva, formado sobre columnas metálicas de doble altura y separado de las otras dependencias por cerramientos de caoba y cristal, hechos con singular buen gusto, de estilo inglés, muy apropiados para el objeto a que se los dedica.»

La planta superior albergaba las oficinas y las instalaciones técnicas, de las que apenas se da detalle en las noticias.

El Consejo de Administración en pleno estuvo presente, con Parellada a la cabeza, y el invitado de honor fue el alcalde, Francos Rodríguez. Al final del acto, la Peninsular invitó a todos los periodistas a un banquete en el «Ideal Room»"

${ }^{30}$ La Época, 25 de marzo de 1911, p. 2. 


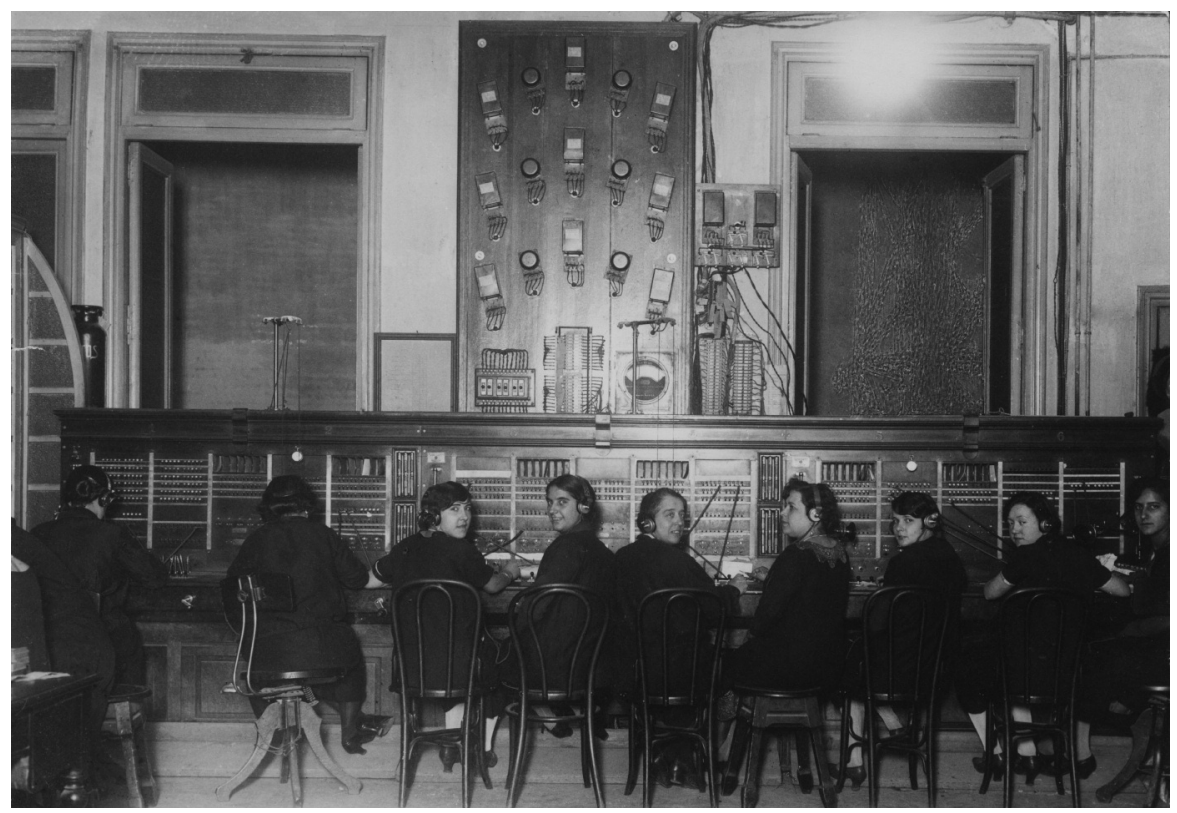

Figura 7: Sala de conmutación de la central de Alcalá 1 en 1926, poco antes de ser desmontada. Fotografía de Alfonso, Archivo Histórico Fotográfico de Telefónica, negativo R-04123.

Este tipo de agasajo se repite años después en todas las inauguraciones de Telefónica.

La vida como central de este edificio no fue muy larga. Tras la integración de la Peninsular en la CTNE en 1924, sus funciones fueron sustituidas por una instalación provisional en la calle Hortaleza ya que Alcalá 1 carecía posibilidades de ampliación. Fue reconvertido en oficinas del Departamento de Publicidad de la CTNE y como tal funcionó hasta la Guerra Civil. Fue demolido en la posguerra.

Hoy resulta difícil entender que estos edificios fueran lugar de encuentro, pero en 1980, Antonio Díaz-Cañabate escribió lo siguiente, al recordar sus años de juventud:

«Una de las pérdidas más sensibles fue sin duda el cierre de la Central de Teléfonos, que vivió muy pocos años en su emplazamiento del comienzo de la calle de Alcalá. [..] ¡Cuantos buenos ratos he pasado allí! Era el más grato y acogedor rincón de la Puerta del Sol. Creo que nadie entraba a hablar por teléfono. Lugar de citas. Lugar de tertulias volanderas. Lugar de bulos y noticiones. Templado en invierno, fresquito en verano. No se podía uno sentar. Había que estar a pie firme. Había quien se tiraba tres y cuatro horas sin sentir. ${ }^{31}$

${ }^{31}$ «La Central de Teléfonos», $A B C, 11$ de mayo de 1980, pág. 15. 


\section{LAS SUBCENTRALES DE CHAMBERI Y SALAMANCA}

Desde 1897 el corazón de la red telefónica era la central de la calle Mayor ${ }^{132}$. En la segunda década del siglo XX, la Compañía Madrileña de Teléfonos se vio en la necesidad de ampliar el servicio con dos «subcentrales», como se llamaban entonces, en los barrios de Salamanca y Chamberí3 ${ }^{3}$. Se adquirieron los solares en las calles de Hermosilla y Jordán, y la elaboración de los proyectos se encomendó a Enrique Martí Perla.

No es mucho lo que sabemos acerca de este arquitecto madrileño, titulado, tras su paso por la Facultad de Ciencias de la Universidad Central ${ }^{34}$, en la Escuela de Arquitectura de Madrid en julio de 1898. Durante los primeros años de su trayectoria profesional, se sintió atraído, siempre dentro de concepciones eclécticas, por el lenguaje modernista en la versión más atemperada que representaba el secesionismo vienés. Es lo que puede apreciarse en las escasas obras documentadas de aquel periodo ${ }^{35}$, entre las que sobresalen las dos subcentrales telefónicas que diseñó y construyó para la Compañía Madrileña de Teléfonos entre los años 1914 y 1917.

Desde el punto de vista arquitectónico y decorativo, las fachadas de estas dos centrales -casi gemelas en su composición y ornamentación, según demuestran los planos originales y las fotografías antiguas-, exhibían un modernismo contenido, concretamente un secesionismo de gran refinamiento y excelente factura ${ }^{36}$. Lógicamente, ambos edificios combinaban la función puramente industrial (instalaciones de maquinaria y taller de reparaciones) con la atención al público (oficinas y locutorios), por lo que el diseño de sus fachadas se cuidó con esmero, al recubrirlas completamente con sillería de piedra artificial y ornamentos de cemento pintado. El clasicismo al que remitían su equilibrada composición, y algunos detalles de las columnas, pilastras, huecos, antepechos y balaustradas, era trascendido por una estilización formal y estaba acompañado por

32 El edificio conocido popularmente como «Las Casas del Cordero» (1842-1845) es una pieza destacada de la arquitectura madrileña, de Juan José Sánchez Pescador. La instalación de la central coronó la casa con el «Kiosko del teléfono», un templete que sobrevivió hasta 1927.

${ }^{33}$ En una nota de la Compañía, se indica que la central de Mayor 1 ya no admitía ninguna ampliación y que eso obligó a llevar a cabo las obras con carácter de urgencia. ABC, 4 de junio de1926, pág. 22.

${ }^{34}$ Expediente académico en el Archivo Histórico Nacional, Universidades, 5831, Exp.16. Fue director de la Escuela de Artes y Oficios de Madrid y de la Academia Martí-Rines, así como vicesecretario de la Junta del Colegio Oficial de Arquitectos en junio de 1936. En los años 20 se especializó en la realización de viviendas para colonias residenciales. Lo más probable es que muriese de forma violenta en Madrid, ya que su nombre figura en una esquela colectiva de la «Congregación de Arquitectos de Nra. Sra de Belén» en $A B C$, el 1 de junio de 1939, p. 38, y aparece en el registro de enterrados en el Valle de los Caídos. Según la Gaceta de la República del 30 de diciembre de 1938, núm. 364, p. 1362, fue apartado de la docencia por abandono de destino.

${ }^{35}$ Mención a alguna de ellas se hace en ROCHA ARANDA, Ó. da. Ob. Cit., 2009, pp. 65, 91, 321,359 y 505-507.

${ }^{36}$ Memoria y planos originales en AVM 19-412-25 y 20-439-2. 


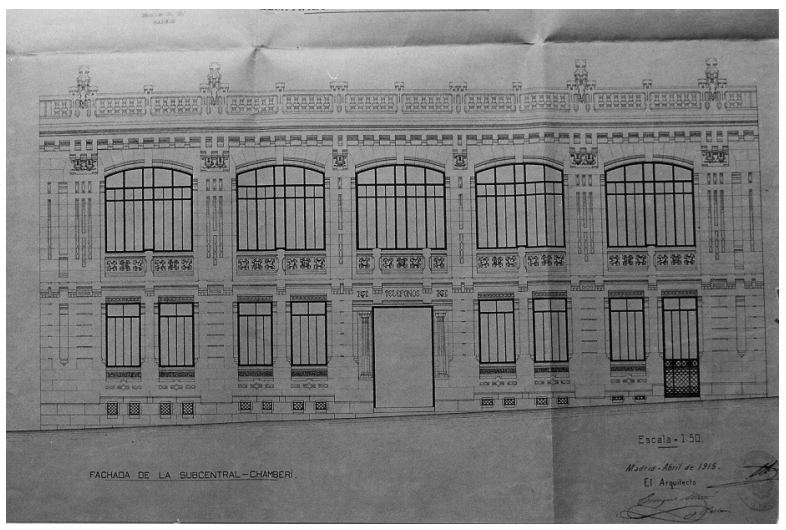

Figura 8: Plano original de la fachada de la subcentral de Jordán. Archivo de la Villa de Madrid

Figura 9: Plano original de la fachada de la subcentral de Hermosilla. Archivo de la Villa de Madrid

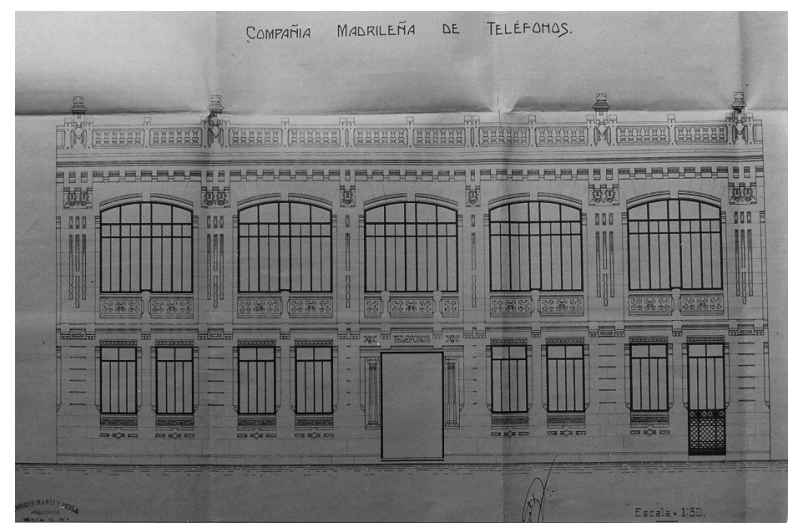

diversos adornos en letreros, apilastrados y remates, que demuestran la cercanía de Martí a las ideas estéticas de la Secesión.

De este modo, el arquitecto pone de manifiesto una idea que puede aplicarse a cierta parte de la arquitectura industrial o comercial erigida en Madrid a comienzos del siglo XX: el hecho de que, entre todas las posibilidades que ofrecían a este tipo de edificios las diferentes corrientes del modernismo internacional, el secesionismo fue la elegida mayoritariamente debido a su sencillez volumétrica, aspiraciones de funcionalidad y continencia decorativa. Todo ello en comparación con otras tendencias modernistas, mucho más seducidas por la complejidad compositiva y la exuberancia ornamental, caso del art nouveau francés, las cuales -conviene recordarlo- tantas críticas recibieron entonces desde casi todos los estamentos arquitectónicos. ${ }^{37}$

${ }^{37}$ Acerca de la problemática relativa a la aplicación del modernismo en la arquitectura industrial y comercial madrileña, véase ROCHA ARANDA, Ó. da. Ob. Cit., 2009, pp. 343-404. 


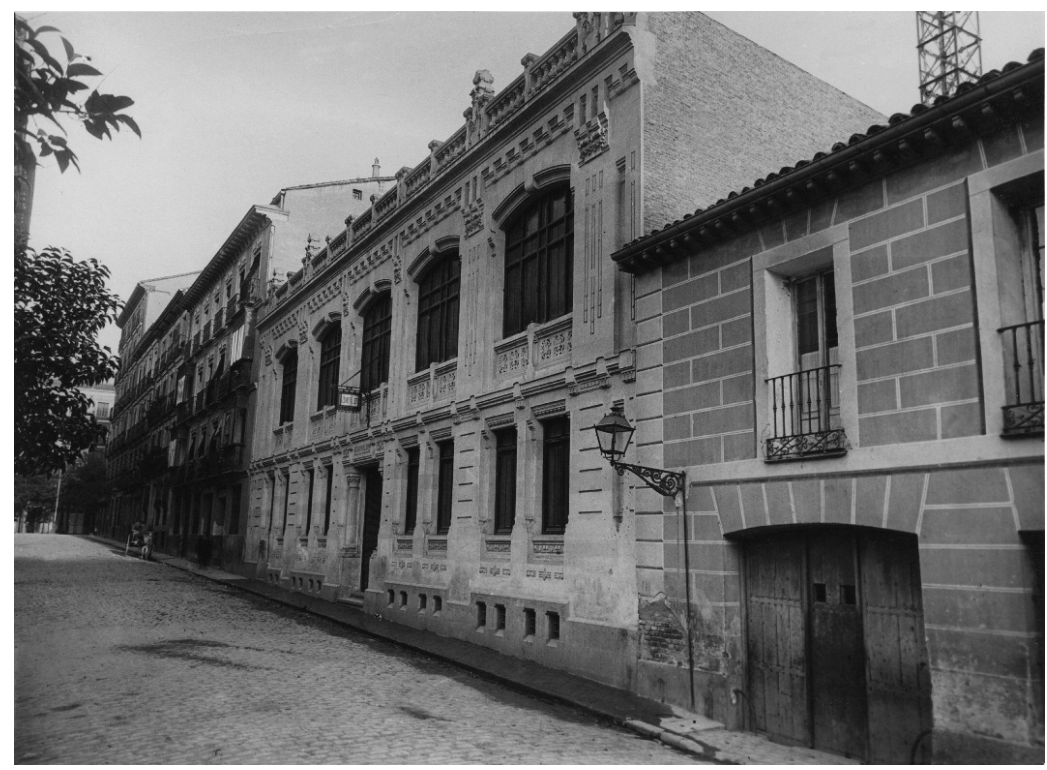

Figura 10: Fachada de la subcentral de Jordán en 1924. Fotografía de Marín, Archivo Histórico Fotográfico de Telefónica, negativo R-04812.

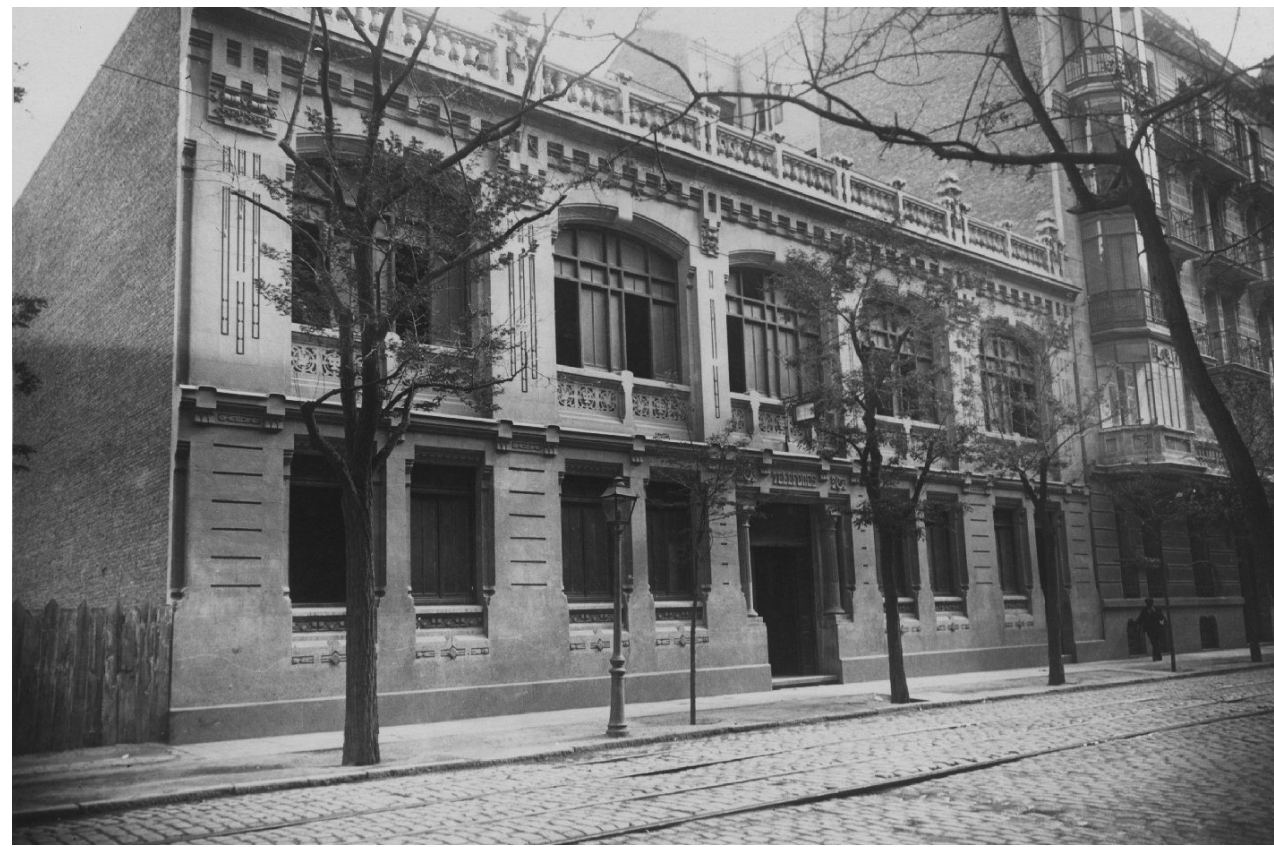

Figura 11: Fachada de la subcentral de Hermosilla en 1924. Fotografía de Marín, Archivo Histórico Fotográfico de Telefónica, negativo R-04847. 


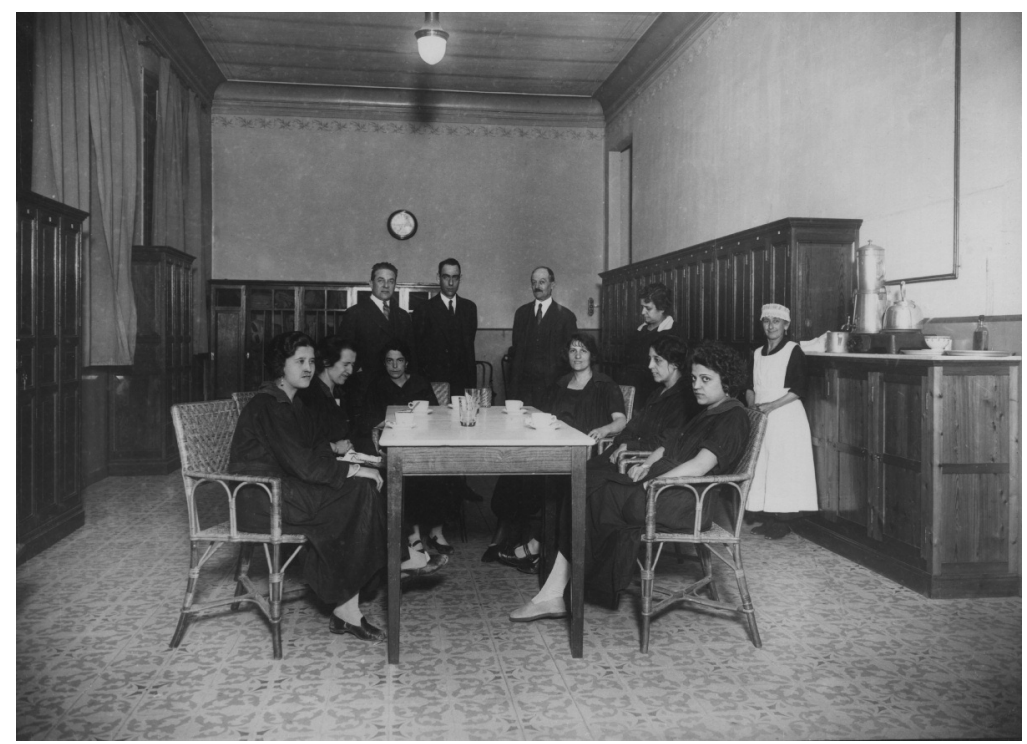

Figura 12: Sala de descanso de la central de la calle Jordán, en una fotografía de Marín. Archivo Histórico Fotográfico de Telefónica, negativo R-07494.

La central de la calle Jordán se inauguró a mediados de 1916 con 3.480 líneas, y pocas semanas después entró en funcionamiento Hermosilla con 3.600, aunque no se completó hasta marzo de 1917. Los equipos eran del tipo «de batería central», la segunda generación de la telefonía manual. A diferencia de los más primitivos teléfonos «magneto», las baterías que alimentan el circuito de conversación se instalaban en el edificio de la compañía. Eso obligaba a un diseño industrial con una estructura calculada para soportar la carga de estos elementos y de otros auxiliares como los generadores. Esta circunstancia técnica impulsó la arquitectura telefónica en todo el mundo por esas fechas. El material se fabricó en Estados Unidos $^{38}$, y el redactor de Blanco y Negro escribió con melancolía:

«Las Centrales de Chamberí (Jordán) y Salamanca son de las mejores del mundo (!Viva Madrid!). Y han sido montadas por Compañías extranjeras (¡Adiós, Madrid!). $\gg^{39}$

El reportaje incluía una descripción de la sala donde trabajaban las operadoras:

«Cada telefonista tiene en el tablero horizontal de su mesa o cuadro 120 jacks de otros tantos abonados a quienes sirve, y en el tablero vertical, que se llama «el múltiple», y que parece un panal inmenso, tiene a su alcance jtodos los jacks de to-

${ }^{38} A B C, 30$ de junio de 1915, p. 18.

${ }^{39}$ LUQUE, FERNANDO. «Las arterias de la palabra», Blanco y Negro, 5 de enero de 1919, pp. 29-34. 


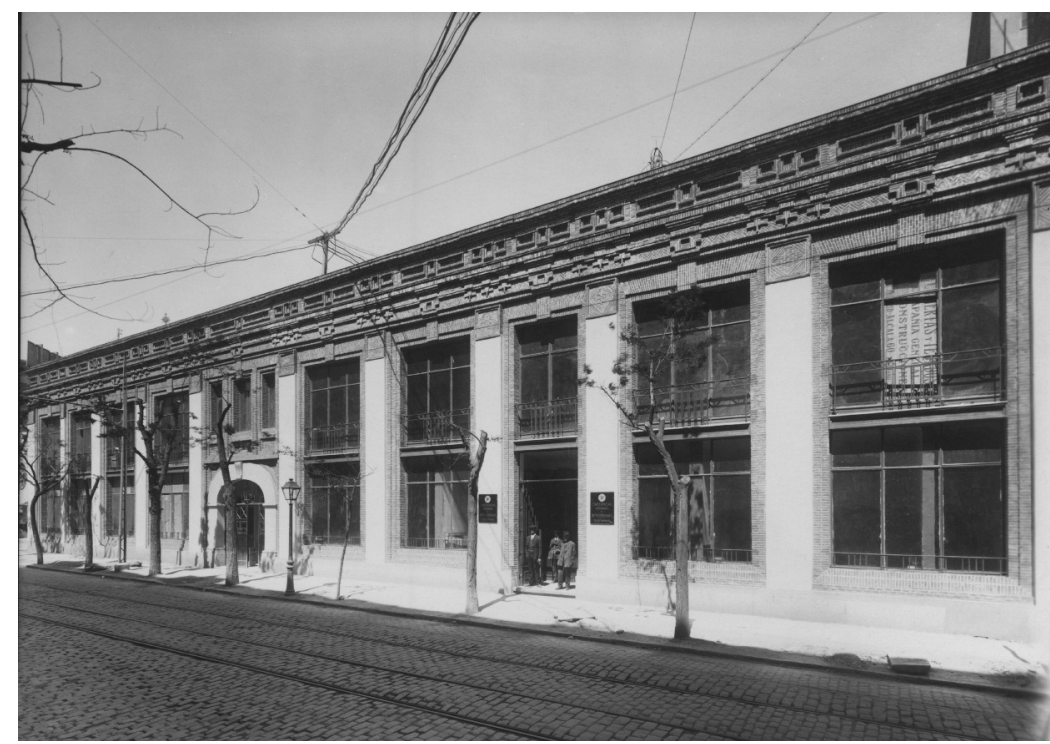

Figura 13: Fachada de la central de la calle Hermosilla. Fotografía de Alfonso, 1926. A la derecha puede verse la central primitiva integrada en el conjunto resultante, los ordenanzas están en lo que era la puerta principal de acceso antes de las obras. Archivo Histórico Fotográfico de Telefónica, negativo R-04799.

dos los abonados de la red! Extraña que no se vuelvan locas y que no prorrumpan de repente en grandes carcajadas: ¡Jack! ¡Jack! ¡Jack!»

Estas mujeres pasaban muchas horas sentadas y necesitaban dependencias como vestuarios, servicios y una sala de descanso que solía servir también como comedor.

Cuando la CTNE se diseñó la red automática de Madrid, decidió reaprovechar estos edificios ya que por sus características constructivas eran los únicos del Sistema Peninsular en los que se que podían acomodar los nuevos equipos. Jordán se remodeló internamente y mantuvo su traza original hasta los años 70 , cuando se transformó hasta resultar irreconocible en la actualidad.

En Hermosilla se construyó un cuerpo adicional sobre el solar colindante, según proyecto de Ignacio de Cárdenas (1898-1979, t. 1924), jefe del Departamento de Edificaciones que por entonces estaba también proyectando el rascacielos de Gran Vía. La fachada de Martí Perla se perdió para adecuar el aspecto externo al del nuevo proyecto. La ceremonia de inauguración de la red automática de Madrid, con asistencia de Alfonso XIII se celebró en este edificio el 29 de diciembre de 1926, por ser el más representativo del que disponía la CTNE en ese momento. Pronto cumplirá el primer siglo de servicio ininterrumpido, es la central más veterana de España. 


\section{CONCLUSIONES}

La débil implantación del teléfono en España impidió la aparición de una arquitectura propia de este negocio hasta la segunda década del siglo XX. El conjunto más notable, antes de la creación de la CTNE en 1924, lo forman las tres centrales que el Grupo Peninsular construyó en Madrid. Esta empresa privada aplicó la idea de aunar utilidad y representación en sus edificios, que había desarrollado AT\&T, como uno de los elementos principales de su política de relaciones públicas. Dentro del auge del eclecticismo que vivía la arquitectura madrileña del momento, el lenguaje modernista es el elemento común a las centrales, con una fuerte influencia catalana en el caso de Alcalá 1 y de la Secesión vienesa en Jordán y Hermosilla. En la primera, que desempeñaba la función de sede visible del Grupo en la capital, se produjo un gran despliegue ornamental en la fachada, con la participación del mosaicista Lluís Brú. Se ha aportado documentación original que contribuye a aclarar cuestiones no dilucidadas hasta el momento, como la autoría de Alcalá 1, y material gráfico de gran valor para conocer el aspecto de estos edificios desaparecidos. 